\title{
Airway inflammation in Japanese COPD patients compared with smoking and nonsmoking controls
}

\author{
This article was published in the following Dove Press journal: \\ International Journal of COPD \\ 23 January 2015 \\ Number of times this article has been viewed
}

\author{
Nobuhisa Ishikawa' \\ Noboru Hattori ${ }^{2}$ \\ Nobuoki Kohno² \\ Akihiro Kobayashi ${ }^{3}$ \\ Tomoyuki Hayamizu ${ }^{4}$ \\ Malcolm Johnson ${ }^{5}$ \\ 'Department of Respiratory Medicine, \\ Hiroshima Prefectural Hospital, \\ Hiroshima, Japan; ${ }^{2}$ Department \\ of Molecular and Internal \\ Medicine, Hiroshima University, \\ Hiroshima, Japan; ${ }^{3}$ Biomedical Data \\ Science Department, ${ }^{4}$ Medical \\ Affairs Respiratory Department, \\ GlaxoSmithKline Shibuya-ku, Tokyo, \\ Japan; ${ }^{5}$ Respiratory Global Franchise, \\ GlaxoSmithKline, Uxbridge, UK
}

Purpose: To assess the importance of inflammation in chronic obstructive pulmonary disease (COPD) by measuring airway and systemic inflammatory biomarkers in Japanese patients with the disease and relevant control groups.

Patients and methods: This was the first study of its type in Japanese COPD patients. It was a non-treatment study in which 100 participants were enrolled into one of three groups: nonsmoking controls, current or ex-smoking controls, and COPD patients. All participants underwent standard lung function assessments and provided sputum and blood samples from which the numbers of inflammatory cells and concentrations of biomarkers were measured, using standard procedures.

Results: The overall trends observed in levels of inflammatory cells and biomarkers in sputum and blood in COPD were consistent with previous reports in Western studies. Increasing levels of neutrophils, interleukin 8 (IL-8), surfactant protein D (SP-D), and Krebs von den Lungen 6 (KL-6) in sputum and clara cell 16 (CC-16), high-sensitivity C-reactive protein (hs-CRP), and KL-6 in serum and plasma fibrinogen were seen in the Japanese COPD patients compared with the non-COPD control participants. In sputum, significant correlations were seen between total cell count and matrix metalloproteinase 9 (MMP-9; $P<0.001$ ), neutrophils and MMP-9 $(P<0.001)$, macrophages and KL-6 $(P<0.01)$, total cell count and IL-8 $(P<0.05)$, neutrophils and IL-8 $(P<0.05)$, and macrophages and MMP-9 $(P<0.05)$. Significant correlations were also observed between some inflammatory cells in sputum and biomarkers in serum, with the most significant between serum $\mathrm{CC}-16$ and both total cell count $(P<0.005)$ and neutrophils $(P<0.005)$ in sputum.

Conclusion: These results provide evidence for the first time that COPD in Japanese patients is a multicomponent disease, involving both airway and systemic inflammation, in addition to airway obstruction. Therefore, intervention with anti-inflammatory therapy may provide additional benefit in disease management of COPD in Japan.

Keywords: chronic obstructive pulmonary disease, inflammatory cells, biomarkers, sputum, serum

\section{Introduction}

Chronic obstructive pulmonary disease (COPD) is the fourth leading cause of death globally, with a projected increase in burden resulting from continued exposure to COPD risk factors and an aging population. ${ }^{1}$ From 1995 to 2005 , a survey by the Japanese Ministry of Health and Welfare reported a prevalence of COPD of $0.2 \%-0.4 \%$ in Japan, ${ }^{2}$ and there is a belief that COPD in Japan is different than in the West. ${ }^{3}$ However, recent data indicate the prevalence of airflow limitation to be $10.9 \%$, suggesting under-recognition of COPD in Japan, ${ }^{3}$ and the phenotypic distribution is similar to that previously described in Western studies. ${ }^{4}$ COPD is an inflammatory lung disease caused by long-term inhalation exposure to noxious substances, most commonly
Correspondence: Tomoyuki Hayamizu Medical Affairs Respiratory Department, GlaxoSmithKline, 6-I5 Sendagaya

4-chome, Shibuya-ku, Tokyo,

I5I-8566 Japan

Tel +8I 357865336

Email tomoyuki.3.hayamizu@gsk.com 
tobacco smoke. ${ }^{1,4}$ It is characterized by incompletely reversible airflow limitation, resulting from varying degrees of small airways disease and emphysema, and it is progressive. ${ }^{1}$ Inflammation of the respiratory tract may be involved both in the development of COPD and the progression of airflow limitation. ${ }^{1,5}$ Indeed, Japanese and world guidelines define COPD as an inflammatory disease of the lung. ${ }^{1,2}$ However, increasing evidence suggests COPD symptoms are also associated with abnormal systemic inflammatory responses, making COPD a multicomponent disease. ${ }^{6-9}$ Increased airway and systemic inflammation have been associated with COPD exacerbations and physiological changes such as hyperinflation. ${ }^{10,11}$

To this end, inflammatory biomarkers have become a useful means of characterizing the extent of both airway and systemic inflammation associated with COPD and for measuring the anti-inflammatory effects of treatment, especially given the high variability observed in the rate of decline of forced expiratory volume in 1 second $\left(\mathrm{FEV}_{1}\right)$ as an endpoint. ${ }^{12-14}$ However, serum and sputum inflammatory biomarkers in Japanese patients with COPD have not been studied extensively. In this study, we have selected a panel of biomarkers based on previous studies, such as ECLIPSE (Evaluation of COPD Longitudinally to Identify Predictive Surrogate Endpoints), in COPD. For example, in exacerbations of COPD, it has been reported that inflammatory cells such as neutrophils and eosinophils are increased in sputum. ${ }^{11}$ Interleukin 8 (IL-8) in sputum is associated with increased chemotaxis of activated neutrophils and eosinophils. ${ }^{15}$ Matrix metalloproteinase 9 (MMP-9) has also been related to the pathogenesis of COPD, ${ }^{15}$ and clara cell secretory protein 16 (CC-16) in blood and pulmonary surfactant protein (SP) A and Krebs von den Lungen 6 (KL-6) have been postulated to represent a biomarker, especially for fibrosis of the lung.

The novelty and importance of the present study is that it is the first to assess both airway and systemic inflammation (using induced sputum and serum samples) in Japanese COPD patients compared with smoking and nonsmoking control participants. It proved impossible in this population to include a group of COPD patients without a smoking history.

\section{Materials and methods Subjects}

A total of 100 Japanese men and women, aged 40 years or older, were enrolled who were either nonsmokers (nonsmoking control participants) who had not smoked for the past 6 months with a pack history of 1 pack a year or less and no diagnosis of COPD, current or ex-smokers (smoking control participants) with a pack history of 10 or more years and no diagnosis of COPD, or current or ex-smokers with a diagnosis of COPD (COPD patients) with a pack history of 10 or more years and cough or sputum 2 or fewer weeks before entry to the study. The diagnosis of COPD was defined according to the Global Initiative for Chronic Obstructive Lung Disease (GOLD) criteria, with a prebronchodilator $\mathrm{FEV}_{1} /$ forced vital capacity (FVC) lower than 0.7 . $^{1}$ Participants assigned as nonsmoking control patients and smoking control patients had no airway obstruction (prebronchodilator $\mathrm{FEV}_{1} / \mathrm{FVC} \geq 0.7$ ). Participants were excluded if they had a diagnosis of bronchial asthma or any respiratory disorder other than COPD; had undergone lung volume reduction or lung transplant; had a chest X-ray (or computed tomography [CT] scan) indicating major disease other than COPD that may interfere with study assessments; had a respiratory infection within 4 weeks before screening; used inhaled corticosteroids and systemic corticosteroids or low-dose xanthines (use at a regular dose was allowable) 2 or fewer weeks before screening; had a bacterial infection, viral infection (including viral hepatitis), or systemic inflammation at enrolment; or had a known $\alpha 1$-antitrypsin deficiency. All participants gave, in writing, their informed consent and permission to use their samples.

\section{Study design}

This was a non-treatment study conducted between November 2012 (first subject, first visit) and November 2013 (statistical analysis completed) at the Hiroshima University Hospital, Japan. The study was conducted in accordance with the ethical principles of the Declaration of Helsinki and was approved by the Ethics Committee of Hiroshima University Hospital.

Participants attended the study center once for an initial medical examination and study-related assessments. If participants did not reach their cough and sputum status, they could return to the site for a retest 2 or more weeks after the initial visit. Undesirable medical events, including serious adverse events, were monitored during and between both study visits.

\section{Assessments}

At the study visit, participants underwent standard lung function assessments $\left(\mathrm{FEV}_{1}, \mathrm{FVC}, \%\right.$ predicted $\mathrm{FEV}_{1}$ and $\mathrm{FEV}_{1} / \mathrm{FVC}^{16}$ and had a chest X-ray if one had not been performed within 6 months of the study visit. Impulse 
Oscillation System (IOS) parameters were measured, as previously described. ${ }^{17,18}$ Values at an airway resistance of $5 \mathrm{~Hz}(\mathrm{R} 5)$ and $20 \mathrm{~Hz}(\mathrm{R} 20)$ and airway reactance of $5 \mathrm{~Hz}$ (X5) were used for analysis. Airway resistance and reactance were assessed as measurements averaged over several tidal breaths (whole-breath analysis). Sputum specimens were obtained according to guidelines of the European Respiratory Society's Task Force, as previously described. ${ }^{19,20}$ In brief, a sputum induction procedure was conducted using 3\%-5\% hypertonic saline given at 5 minute intervals for a maximum of 15 minutes via an ultrasonic nebulizer NE-U12 (Omron Co, Kyoto, Japan). Inflammatory cell counts (neutrophil, eosinophil, lymphocyte, macrophage, and total inflammatory cell) from induced sputum were measured using fixed cell samples by Diff-Quick staining in the Hiroshima University laboratory. Inflammatory biomarkers were measured using standard immunochemical assays by SRL Medisearch Inc (Sagamihara, Japan) collected from sputum supernatant; IL-8 [enzyme-linked immunosorbent assay \{ELISA\}], KL-6 [electro-chemiluminescence immunoassay], SP-A [enzyme immunoassay $\{$ EIA $\}$ ], SP-D [EIA], hs-CRP [latex-enhanced nephelometry], or MMP-9 [EIA], serum; IL-8 [ELISA], KL-6 [enzyme-linked immune-culture assay], CC-16 [ELISA], SP-A [EIA], SP-D [EIA], hs-CRP [latex-enhanced nephelometry], and plasma; fibrinogen, measured using the thrombin clotting time test with a detection limit of $20 \mathrm{mg} /$ dL. CC-16 was not measured in sputum, as previous studies ${ }^{14}$ showed it was not a descriptive factor in COPD.

\section{Statistical methods}

The target number of participants was 100, of whom 50 were COPD patients, 30 were smoking control participants, and 20 were nonsmoking control participants. Inflammatory cell counts, the percentage of inflammatory cells, and concentration of inflammatory biomarkers were analyzed using the Dunnett's multiple comparison nonparametric test to compare the COPD, non-COPD smoker, and non-COPD nonsmoker groups. Stratified analyses were then conducted according to subject baseline factors. The per protocol (PP) set was the primary data set for analysis. Correlation between variables was assessed by Spearman's rank correlation coefficient.

\section{Results Subject population}

Demographic data are summarized in Table 1. The three subject groups were generally similar with respect to age, height, and weight; the smoking control participant group and COPD group were similar with respect to the number of pack-years. However, there was a predictable statistically significant difference between COPD patients versus

Table I Summary of demographics and spirometry measurements

\begin{tabular}{|c|c|c|c|}
\hline Demographics and measurements & Nonsmoker control & Smoker control & COPD \\
\hline Participants, $n$ & 20 & 30 & 47 \\
\hline \multicolumn{4}{|l|}{ Demographics } \\
\hline Age, years & $59.0 \pm 10.2$ & $62.7 \pm 12.1$ & $70.8 \pm 8.1$ \\
\hline Sex, males/females & $10 / 10$ & $28 / 2$ & $45 / 2$ \\
\hline Height, $\mathrm{cm}$ & $160.6 \pm 7.3$ & $165.8 \pm 7.5$ & $163.5 \pm 6.7$ \\
\hline Weight, kg & $62.3 \pm 11.0$ & $66.6 \pm 10.0$ & $62.3 \pm 9.6$ \\
\hline \multicolumn{4}{|l|}{ Smoking history } \\
\hline Current/former/never & $0 / 3 / 17$ & $9 / 21 / 0$ & $13 / 34 / 0$ \\
\hline Number of pack-years & $0.34 \pm 0.3$ & $57.3 \pm 105.9$ & $62.3 \pm 44.7$ \\
\hline \multicolumn{4}{|l|}{ Spirometry } \\
\hline FVC, L & $3.03 \pm 0.69$ & $3.72 \pm 0.94$ & $3.18 \pm 0.76$ \\
\hline $\mathrm{FEV}_{1}, \mathrm{~L}$ & $2.47 \pm 0.55^{*}$ & $2.91 \pm 0.80^{\dagger}$ & $1.92 \pm 0.56$ \\
\hline $\mathrm{FEV}_{1}, \%$ predicted & $95.0 \pm 11.7^{*}$ & $96.5 \pm 16.9^{\dagger}$ & $71.3 \pm 17.4$ \\
\hline $\mathrm{FEV}_{1} / \mathrm{FVC}$ & $81.8 \pm 6.8^{\dagger}$ & $78.1 \pm 5.6^{\dagger}$ & $60.2 \pm 9.1$ \\
\hline \multicolumn{4}{|c|}{ Whole-breath Impulse Oscillation System results } \\
\hline $\mathrm{R} 5, \mathrm{kPa} / \mathrm{L} / \mathrm{second}$ & $0.283 \pm 0.113^{\ddagger}$ & $0.242 \pm 0.121 \pi$ & $0.34 I \pm 0.149$ \\
\hline $\mathrm{R} 20, \mathrm{kPa} / \mathrm{L} / \mathrm{second}$ & $0.248 \pm 0.089 \S$ & $0.219 \pm 0.076$ & $0.262 \pm 0.078$ \\
\hline $\mathrm{X} 5, \mathrm{kPa} / \mathrm{L} / \mathrm{second}$ & $-0.112 \pm 0.03 \S$ & $-0.106 \pm 0.09 \ddagger$ & $-0.170 \pm 0.12$ \\
\hline
\end{tabular}

Notes: Demographic data are shown as number of subjects or raw means \pm standard deviation, as appropriate. Spirometry data are shown as number of subjects or adjusted means \pm standard error, as appropriate. The Dunnett's test was conducted by comparing with each adjusted mean values. $* P<0.0005$ (difference between COPD and nonsmoker control or smoker control groups, by the Dunnett's test). ${ }^{\dagger} P<0.000$ I (difference between COPD and nonsmoker control or smoker control groups, by the Dunnett's test). ${ }^{\ddagger}<0.01$ (difference between COPD and nonsmoker control or smoker control groups, by the Dunnett's test). ${ }^{\pi}<0.005$ (difference between COPD and nonsmoker control or smoker control groups, by the Dunnett's test). ${ }^{\$} P<0.05$ (difference between COPD and nonsmoker control or smoker control groups, by the Dunnett's test).

Abbreviations: COPD, chronic obstructive pulmonary disease; $\mathrm{FEV}_{\text {, }}$, forced expiratory volume in I second; FVC, forced vital capacity. 
both smoking control participants and nonsmoking control participants with respect to $\mathrm{FEV}_{1}, \mathrm{FEV}_{1} \%$ predicted, and $\mathrm{FEV}_{1} / \mathrm{FVC}$. There was also a statistically significant difference between COPD patients and both smoking control participants and nonsmoking control participants with respect to all the IOS parameters, with the exception of R20, a marker of mean airway resistance of central airways, for COPD patients versus smoking control participants.

The PP population comprised 97 of 100 participants, as three participants from the COPD patient group were excluded from PP analysis because of concomitant illnesses of fibrosis of the lung, asthma, and fibrosis of the lung and kidney cancer, respectively. One participant experienced a serious adverse event (bronchial asthma attack) during the sputum induction procedure and was not enrolled in the study.

\section{Inflammatory cells in sputum}

Sputum inflammatory cell data are summarized in Table 2.

Although no statistically significant differences were observed in total cell counts between COPD patients and non-COPD control participants, there was a trend toward an increase in COPD. The mean sputum total cell count \pm standard deviation in the COPD group, smoking control participants, and nonsmoking control participants were $66.5 \times 10^{5} \pm 80.8$ cells $/ \mathrm{mL}, 45.8 \times 10^{5} \pm 40.4$ cells $/ \mathrm{mL}$ and $39.5 \times 10^{5} \pm 30.4$ cells $/ \mathrm{mL}$, respectively.

Similarly, no statistically significant differences were observed between the COPD patients and non-COPD control participants in relation to induced sputum neutrophils and macrophages. However, the mean percentage \pm standard deviation of neutrophils in the COPD group, smoking control participants, and nonsmoking control participants were $76.3 \% \pm 15.7 \%, 69.5 \% \pm 20.3 \%$, and $67.4 \% \pm 24.3 \%$, respectively, again indicating a trend toward an increase in COPD. In contrast, the absolute numbers of macrophages were $8.7 \times 10^{5}, 9.5 \times 10^{5}$, and $12.3 \times 10^{5}$ cells $/ \mathrm{mL}$ in the COPD patients, smoking control participants, and nonsmoking control participants, and the mean percentages were $16.6 \% \pm 13.3 \%, 23.1 \% \pm 18.0 \%$, and $25.4 \% \pm 23.7 \%$, respectively, suggesting a marked decrease in COPD patients.

\section{Levels of biomarkers in sputum and blood}

Biomarker data in sputum and blood are summarized in Table 2.

Median sputum IL-8 levels were significantly higher in COPD patients $(551.0 \mathrm{pg} / \mathrm{mL})$ than in the smoking control

Table 2 Summary of inflammatory cells and biomarkers in sputum and blood

\begin{tabular}{|c|c|c|c|}
\hline Inflammatory biomarkers & Nonsmoker control & Smoker control & $\begin{array}{l}\text { Chronic obstructive } \\
\text { pulmonary disease }\end{array}$ \\
\hline Participants, $\mathrm{n}$ & 20 & 30 & 47 \\
\hline \multicolumn{4}{|l|}{ Inflammatory cells (sputum) } \\
\hline Total cell count, $\times 10^{5}$ cells $/ \mathrm{mL}$ & $39.5 \pm 30.4$ & $45.8 \pm 40.4$ & $66.5 \pm 80.8$ \\
\hline Neutrophil count, $\times 10^{5}$ cells $/ \mathrm{mL}$ & $24.6 \pm 21.5$ & $32.7 \pm 32.1$ & $53.6 \pm 73.6$ \\
\hline Macrophage count, $\times 10^{5}$ cells $/ \mathrm{mL}$ & $12.3 \pm 21.6$ & $9.5 \pm 10.0$ & $8.7 \pm 9.1$ \\
\hline Sputum neutrophils, \% & $67.4 \pm 24.3$ & $69.5 \pm 20.3$ & $76.3 \pm 15.7$ \\
\hline Sputum macrophages, \% & $25.4 \pm 23.7$ & $23.1 \pm 18.0$ & $16.6 \pm 13.3$ \\
\hline \multicolumn{4}{|l|}{ Biomarkers (sputum) } \\
\hline IL-8, pg/mL & 336.0 & $263.0^{*}$ & 551.0 \\
\hline MMP-9, ng/mL & 80.0 & 90.0 & 130.0 \\
\hline $\mathrm{SP}-\mathrm{A}, \mathrm{ng} / \mathrm{mL}$ & 95.16 & 140.0 & 158.0 \\
\hline $\mathrm{SP}-\mathrm{D}, \mathrm{ng} / \mathrm{mL}$ & 21.1 & 24.1 & 36.7 \\
\hline $\mathrm{KL}-6, \mathrm{U} / \mathrm{mL}$ & 42.8 & 44.5 & 71.5 \\
\hline \multicolumn{4}{|l|}{ Biomarkers (serum) } \\
\hline IL-8, pg/mL & 5.5 & 5.4 & 6.0 \\
\hline hs-CRP, ng/dL & 327.0 & 500.0 & 594.0 \\
\hline CC-16, ng/mL & 5.6 & 6.6 & 8.5 \\
\hline $\mathrm{SP}-\mathrm{A}, \mathrm{ng} / \mathrm{mL}$ & 27.0 & 38.4 & 39.5 \\
\hline $\mathrm{SP}-\mathrm{D}, \mathrm{ng} / \mathrm{mL}$ & 45.5 & 65.2 & 59.6 \\
\hline $\mathrm{KL}-6, \mathrm{U} / \mathrm{mL}$ & 209.5 & 248.5 & 285.5 \\
\hline \multicolumn{4}{|l|}{ Biomarkers (plasma) } \\
\hline Fibrinogen, mg/dL & 289.0 & 303.5 & 300.0 \\
\hline
\end{tabular}

Notes: Sputum inflammatory cell and serum biomarker data are shown as mean \pm standard deviation; sputum biomarker data are shown as median value. The nonparametric Dunnett's test was conducted by comparing with each raw median value. $* P<0.05$ (difference between patients with COPD and smoker control patients, by the nonparametric Dunnett's test).

Abbreviations: IL-8, interleukin 8; MMP-9, matrix metalloproteinase 9; SP-A, surfactant protein A; SP-D, surfactant protein D; KL-6, Krebs von den Lungen 6; hs-CRP, high-sensitivity C-reactive protein; CC-16, clara cell 16. 
participants $(263.0 \mathrm{pg} / \mathrm{mL})(P<0.05)$. Although overall, the levels of MMP-9, SP-A, SP-D, and KL-6 in sputum were not significantly different between COPD patients and the control groups, levels of SP-D and KL-6 tended to be higher in the COPD patients compared with both non-COPD control groups.

Mean levels of serum CC-16, hs-CRP, and KL-6 and plasma fibrinogen were also higher in COPD patients compared with the non-COPD control participants, with the lowest values generally seen in the nonsmoking group. However, none of the differences seen between the COPD patients and control groups were significantly different for any of the serum biomarkers.

\section{Correlation between sputum inflammatory cells and biomarkers in sputum and serum in COPD patients}

A summary of correlations in the COPD patients is given in Table 3 and Table 4.

Significant correlations were observed between some inflammatory cells in sputum and biomarkers in sputum (Table 3 ) in the COPD patients, with the most significant correlations seen between total cell count and MMP-9 $(P<0.001)$, neutrophils and MMP-9 $(P<0.001)$, and macrophages and KL-6 $(P<0.01)$. Other significant correlations were observed between total cell count and IL-8 $(P<0.05)$, neutrophils and IL-8 $(P<0.05)$, and macrophages and MMP-9 $(P<0.05)$ (Table 3$)$.

Although not showing a clear association between lung and systemic biomarkers of inflammation, which has been reported previously, significant correlations were observed between some inflammatory cells in sputum and biomarkers in serum (Table 4), with the most significant correlations observed between serum CC-16 and both sputum total cell count $(P<0.005)$ and neutrophils $(P<0.005)$.

\section{Discussion}

COPD is a complex disease involving many different types of inflammatory and structural cells, with increasing evidence that both pulmonary and systemic inflammatory processes are involved. ${ }^{4,21}$ To add to the complexity, COPD is also a heterogeneous disease with interpatient variability. ${ }^{22}$ Despite this complexity and heterogeneity, the overall trends and correlations observed in this study in levels of sputum inflammatory cells and sputum and serum biomarkers support the presence of pulmonary and systemic inflammation in Japanese COPD patients.

In induced sputum, the higher total cell count and neutrophil levels tended to be observed in the COPD patients compared with the non-COPD control participants; this agrees with previous data ${ }^{4}$ and provides evidence of pulmonary inflammatory responses occurring in the airways of Japanese COPD patients. However, there was a statistically significant difference between COPD patients and both smoking control participants and nonsmoking control participants with respect to $\mathrm{FEV}_{1}, \mathrm{FEV}_{1}$ \% predicted, and $\mathrm{FEV}_{1} / \mathrm{FVC}$, suggesting spirometry is essential in the diagnosis and assessment of severity of COPD. Indeed, studies have shown that sputum neutrophils have been directly correlated to the rate of annual decline in $\mathrm{FEV}_{1} \cdot{ }^{23}$ Furthermore, IOS parameters also differ between COPD patients and both smoking control participants and nonsmoking control participants. We note that IOS is a novel and noninvasive method of evaluating respiratory resistance and reactance.

Macrophages play a pivotal role in COPD pathophysiology. They are activated by cigarette smoke extract to release inflammatory mediators, thus providing a cellular mechanism by which smoking is linked with inflammation. ${ }^{4}$ Marked increases in the number of macrophages in patients with COPD have been reported. ${ }^{4,24}$ However, in our study, macrophage levels in induced sputum tended to decrease in COPD patients compared with the non-COPD control participants, perhaps indicating that macrophages were being consumed by the inflammatory process. This concurs with several previous reports, where there was a decrease in the number of macrophages in COPD. ${ }^{25,26}$

The significantly higher levels of sputum IL-8 in COPD patients compared with in the smoking control group and its correlation with the numbers of neutrophils suggest IL-8 may be secreted into sputum and then acts as a chemoattractant

Table 3 Summary of correlation between sputum inflammatory cell counts and sputum biomarkers in patients with COPD

\begin{tabular}{|c|c|c|c|c|c|}
\hline \multirow[t]{2}{*}{ COPD $(\mathrm{N}=47)$} & \multicolumn{5}{|c|}{ Sputum } \\
\hline & IL-8, pg/mL & MMP-9, ng/mL & SP-A, ng/mL & SP-D, ng/mL & KL-6, U/mL \\
\hline \multicolumn{6}{|l|}{ Sputum } \\
\hline Number of total cells, $\times 10^{5}$ cells $/ \mathrm{ml}$ & $0.3493 *$ & $0.5337^{\dagger}$ & 0.1655 & 0.1077 & 0.2329 \\
\hline Number of neutrophils, $\times 10^{5}$ cells $/ \mathrm{ml}$ & $0.3156^{*}$ & $0.5073^{\dagger}$ & 0.1466 & 0.0967 & 0.1908 \\
\hline Number of macrophages, $\times 10^{5}$ cells $/ \mathrm{ml}$ & 0.2758 & $0.3038 *$ & 0.1977 & 0.2576 & $0.4058^{\ddagger}$ \\
\hline
\end{tabular}

Notes: $* P<0.05,{ }^{\ddagger} P<0.01,{ }^{\dagger} P<0.001$ (correlation between variables, by Spearman's rank correlation coefficient).

Abbreviations: COPD, chronic obstructive pulmonary disease; IL-8, interleukin 8; MMP-9, matrix metalloproteinase 9; SP-A, surfactant protein A; SP-D, surfactant protein D; KL-6, Krebs von den Lungen 6. 
Table 4 Summary of correlation coefficient between sputum inflammatory cell counts and serum biomarkers in COPD patients

\begin{tabular}{lllllll}
\hline COPD (N=47) & \multicolumn{5}{c}{ Serum } \\
\cline { 2 - 7 } & IL-8, pg/mL & KL-6, U/mL & CC-16, ng/mL & SP-A, ng/mL & SP-D, ng/mL & hs-CRP, ng/dL \\
\hline Sputum & & & & & \\
Number of total cells, $\times 10^{5}$ cells $/ \mathrm{ml}$ & -0.0486 & 0.1990 & $0.4515^{*}$ & -0.0395 & 0.3241 & 0.2175 \\
$\quad$ Number of neutrophils, $\times 10^{5}$ cells $/ \mathrm{ml}$ & -0.0360 & 0.2163 & $0.437 I^{*}$ & -0.0138 & 0.3078 & 0.2155 \\
Number of macrophages, $\times 10^{5}$ cells $/ \mathrm{ml}$ & -0.0713 & 0.0227 & 0.2679 & -0.0013 & 0.1786 & 0.1200 \\
\hline
\end{tabular}

Notes: $* P<0.005$ (correlation between variables, by Spearman's rank correlation coefficient).

Abbreviations: COPD, chronic obstructive pulmonary disease; IL-8, interleukin 8; KL-6, Krebs von den Lungen 6; CC-16, clara cell I6; SP-A, surfactant protein A; SP-D, surfactant protein D; hs-CRP, high sensitivity c-reactive protein.

for neutrophils migrating into the airway. Neutrophils are also a major source of IL-8., ${ }^{4,27}$ Similarly, there is a strong correlation between MMP-9 and the number of neutrophils and neutrophils are known to secrete MMP-9.

Higher levels of sputum SP-D, a lung type II pneumocytederived protein, were also observed in COPD patients compared with non-COPD control participants, which is in agreement with previous data in Japanese subjects. ${ }^{19}$ SP-D has been implicated in the regulation of inflammation and pulmonary host defense and was shown to be elevated in COPD patients compared with non-COPD control participants with prolonged cough; in addition, SP-D levels are positively correlated with smoking status. ${ }^{19}$

Serum CC-16 levels generally increase after acute exposure to smoke; however, there are conflicting data with regard to serum levels of CC-16 in COPD. ${ }^{13}$ For example, in the ECLIPSE cohort, serum CC16 levels were decreased in COPD relative to non-COPD control participants, and demographic variability across the study groups was implicated as a potential contributing factor. ${ }^{13}$ Serum CRP is also considered one of the signature biomarkers of systemic inflammation. ${ }^{6,28}$ Although levels are variable, serum hs-CRP tends to be higher in COPD patients compared with in healthy smokers or nonsmokers. ${ }^{29}$ However, as with CC-16, results can be conflicting and may be a result of variable patient selection and differences in the classification of COPD across studies. ${ }^{6}$

As for sputum, serum KL-6 levels also tended to be higher in the COPD patient group than in the non-COPD control participants. Circulating levels of KL-6 are considered to be a sensitive marker for fibrotic lung diseases and are used in clinical practice in Japan, alongside SP-A and SP-D, for the identification of idiopathic pulmonary fibrosis and other types of interstitial lung diseases. ${ }^{19,30}$ The increase in KL-6 in COPD in this study is of interest.

Although this study provides evidence that there is both pulmonary and systemic inflammation in Japanese COPD patients, our results were unable to provide robust evidence of any significant relationships between the pulmonary and systemic components, which agrees with other data. ${ }^{6,15,31,32}$ The main strength of our study was that the COPD patients enrolled represented a typical Japanese patient population. Our study also had limitations, including the small sample size, which restricted the statistical power of the findings. In addition, not all participants had a CT scan during enrolment. In fact, we were able to obtain the CT scan results of only 10/50 COPD patients, and therefore some of the COPD patients included in the analysis may have had undetected lung fibrosis that may have affected biomarker concentrations. Furthermore, the validation and definition of the specificity of these proteins in various phenotypes of COPD (bronchitis vs emphysema predominance) will require further study. Variability in biomarker levels, as seen in our study, especially in induced sputum, and even in stable COPD patients, is well-documented and can confound results. ${ }^{15,33}$ Finally, measuring biomarker levels in induced sputum rather than biopsy samples means the results are more likely to reflect inflammation in the central, rather than lower and peripheral, airways. ${ }^{19}$

\section{Conclusion}

This is the first study to investigate both airway and systemic inflammation in COPD in Japanese subjects compared with the respective smoking and nonsmoking control groups. Our results provide further evidence that COPD in Japanese patients is a multicomponent disease, involving both airway and systemic inflammation, in addition to airway obstruction.

These results suggest that intervention with antiinflammatory therapy may provide additional benefit for disease management of COPD in Japan. This now needs to be considered in a controlled setting.

\section{Acknowledgments}

Funding for this study was provided by GlaxoSmithKline (NCT00356642). All listed authors meet the criteria for authorship set forth by the International Committee for Medical Journal Editors. The authors wish to acknowledge 
the following individuals for their contributions: members of Hiroshima University who participated in subject recruitment: Hiroshi Murai, Yoshinori Haruta, Kazunori Fujitaka, Shinichiro Ohshimo, Hiroshi Iwamoto, and Taku Nakashima. The authors would also like to thank the following members of the GlaxoSmithKline team who developed the study protocol: Etsuko Hayashi, Hideo Kikkawa, and Daisuke Yoshimoto; SRL Medisearch Inc, for performing the biomarker analyses; and the Institute of Japanese Union of Scientists and Engineers, for performing the data management and statistical analysis.

\section{Author contributions}

All authors were involved in the acquisition and analysis of data, drafting and critical revision of the manuscript, and the final approval of the proof to be published.

\section{Disclosure}

AK and TH were employees of GlaxoSmithKline at the time of the study. NK discloses that his university has received research grants from the commercial entity that sponsored the study. NH discloses having received honoraria, and his university has received research grants from the commercial entity that sponsored the study. NI discloses having received honoraria/consulting fees from GlaxoSmithKline for participating on the advisory board meeting, and his university has received research grants from the commercial entity that sponsored the study. MJ is an independent respiratory consultant employed by GlaxoSmithKline to help in the design and conduct of the study and is a shareholder in GlaxoSmithKline, but has no other relationships or activities that could appear to have influenced the submitted work. Medical writing and editorial support in the form of development of draft outline, development of manuscript (all drafts), assembling tables, and collating author comments was provided by Dr Kathryn White of Cathean Ltd, and was funded by GlaxoSmithKline.

\section{References}

1. Global Initiative for Chronic Obstructive Lung Disease. Global Strategy for the Diagnosis, Management, and Prevention of Chronic Obstructive Pulmonary Disease. Global Initiative for Chronic Obstructive Lung Disease. Available from: http://www.goldcopd.com/uploads/users/files/ GOLD_Report_2014_Oct30.pdf. Accessed December 15, 2014.

2. Japanese Respiratory Society. Guidelines for the Diagnosis and Treatment of COPD, 4th edition. Japanese Respiratory Society; 2013. Available from: https://www.jrs.or.jp/modules/guidelines/index.php?content_id=1. Accessed April 19, 2013.

3. Fukuchi Y, Nishimura M, Ichinose M, et al. COPD in Japan: the Nippon COPD Epidemiology study. Respirology. 2004;9(4):458-465.

4. Barnes PJ. Mediators of chronic obstructive pulmonary disease. Pharmacol Rev. 2004;56(4):515-548.
5. Hogg JC, Chu F, Utokaparch S, et al. The nature of small-airway obstruction in chronic obstructive pulmonary disease. $N$ Engl J Med. 2004;350(26):2645-2653.

6. MacNee W. Systemic inflammatory biomarkers and co-morbidities of chronic obstructive pulmonary disease. Ann Med. 2013;45(3):291-300.

7. Huertas A, Palange P. COPD: a multifactorial systemic disease. Ther Adv Respir Dis. 2011;5(3):217-224.

8. Agustí A. Systemic effects of chronic obstructive pulmonary disease: what we know and what we don't know (but should). Proc Am Thorac Soc. 2007;4(7):522-525.

9. van Eeden SF, Sin DD. Chronic obstructive pulmonary disease: a chronic systemic inflammatory disease. Respiration. 2008;75(2):224-238.

10. Wedzicha JA, Seemungal TA. COPD exacerbations: defining their cause and prevention. Lancet. 2007;370(9589):786-796.

11. Fujimoto K, Yasuo M, Urushibata K, Hanaoka M, Koizumi T, Kubo K. Airway inflammation during stable and acutely exacerbated chronic obstructive pulmonary disease. Eur Respir J. 2005;25(4):640-646.

12. Barnes NC, Qiu Y-S, Pavord ID, et al; SCO30005 Study Group. Antiinflammatory effects of salmeterol/fluticasone propionate in chronic obstructive lung disease. Am J Respir Crit Care Med. 2006;173(7):736-743.

13. Lomas DA, Silverman EK, Edwards LD, Miller BE, Coxson HOR, Tal-Singer R; Evaluation of COPD Longitudinally to Identify Predictive Surrogate Endpoints (ECLIPSE) investigators. Evaluation of serum CC-16 as a biomarker for COPD in the ECLIPSE cohort. Thorax. 2008; 63(12):1058-1063.

14. Vestbo J, Edwards LD, Scanlon PD, et al; ECLIPSE Investigators. Changes in forced expiratory volume in 1 second over time in COPD. N Engl J Med. 2011;365(13):1184-1192.

15. Dickens JA, Miller BE, Edwards LD, Silverman EK, Lomas DA, Tal-Singer R; Evaluation of COPD Longitudinally to Identify Surrogate Endpoints (ECLIPSE) study investigators. COPD association and repeatability of blood biomarkers in the ECLIPSE cohort. Respir Res. 2011;12(1):146-155.

16. Miller MR, Hankinson J, Brusasco V, et al; ATS/ERS Task Force. Standardisation of spirometry. Eur Respir J. 2005;26(2):319-338.

17. Sugiyama A, Hattori N, Haruta Y, et al. Characteristics of inspiratory and expiratory reactance in interstitial lung disease. Respir Med. 2013;107(6):875-882.

18. Nakagawa M, Hattori N, Haruta Y, et al. Effect of increasing respiratory rate on airway resistance and reactance in COPD patients. Respirology. Epub 2014 Sep 23.

19. Ishikawa N, Hattori N, Tanaka S, et al. Levels of surfactant proteins A and D and KL-6 are elevated in the induced sputum of chronic obstructive pulmonary disease patients: a sequential sputum analysis. Respiration. 2011;82(1):10-18.

20. Paggiaro PL, Chanez P, Holz O, et al. Sputum induction. Eur Respir J Suppl. 2002;37:3s-8s.

21. Barnes N. Reducing inflammation in COPD: the evidence builds. Thorax. 2007;62(11):927-928.

22. Agusti A, Calverley PMA, Celli B, et al; Evaluation of COPD Longitudinally to Identify Predictive Surrogate Endpoints (ECLIPSE) investigators. Characterisation of COPD heterogeneity in the ECLIPSE cohort. Respir Res. 2010;11(1):122-135.

23. Stănescu D, Sanna A, Veriter C, et al. Airways obstruction, chronic expectoration, and rapid decline of $\mathrm{FEV}_{1}$ in smokers are associated with increased levels of sputum neutrophils. Thorax. 1996;51(3):267-271.

24. Toungoussova O, Migliori GB, Foschino Barbaro MP, et al. Changes in sputum composition during 15 min of sputum induction in healthy subjects and patients with asthma and chronic obstructive pulmonary disease. Respir Med. 2007;101(7):1543-1548.

25. Iwamoto H, Gao J, Koskela J, et al. Differences in plasma and sputum biomarkers between COPD and COPD-asthma overlap. Eur Respir J. 2014;43(2):421-429.

26. Makris D, Vrekoussis T, Izoldi M, et al. Increased apoptosis of neutrophils in induced sputum of COPD patients. Respir Med. 2009; 103(8):1130-1135. 
27. Bazzoni F, Cassatella MA, Rossi F, Ceska M, Dewald B, Baggiolini M. Phagocytosing neutrophils produce and release high amounts of the neutrophil-activating peptide 1/interleukin 8. J Exp Med. 1991; 173(3):771-774.

28. Pinto-Plata VM, Müllerova H, Toso JF, et al. C-reactive protein in patients with COPD, control smokers and non-smokers. Thorax. 2006; 1(1):23-28.

29. van Durme YM, Verhamme KM, Aarnoudse AJ, et al. C-reactive protein levels, haplotypes, and the risk of incident chronic obstructive pulmonary disease. Am J Respir Crit Care Med. 2009;179(5):375-382.

30. Ishikawa N, Hattori N, Yokoyama A, Kohno N. Utility of KL-6/MUC1 in the clinical management of interstitial lung diseases. Respir Investig. 2012;50(1):3-13.
31. Bizeto L, Mazzolini AB, Ribeiro M, Stelmach R, Cukier A, Nunes MPT. Interrelationship between serum and sputum inflammatory mediators in chronic obstructive pulmonary disease. Braz J Med Biol Res. 2008;41(3): 193-198.

32. Röpcke S, Holz O, Lauer G, et al. Repeatability of and relationship between potential COPD biomarkers in bronchoalveolar lavage, bronchial biopsies, serum, and induced sputum. PLOS ONE. 2012;7(10): e46207.

33. Duvoix A, Dickens J, Haq I, et al. Blood fibrinogen as a biomarker of chronic obstructive pulmonary disease. Thorax. 2013;68(7):670-676.

\section{Publish your work in this journal}

The International Journal of COPD is an international, peer-reviewed journal of therapeutics and pharmacology focusing on concise rapid reporting of clinical studies and reviews in COPD. Special focus is given to the pathophysiological processes underlying the disease, intervention programs, patient focused education, and self management protocols.

\section{Dovepress}

This journal is indexed on PubMed Central, MedLine and CAS. The manuscript management system is completely online and includes a very quick and fair peer-review system, which is all easy to use. Visit $\mathrm{http}: / / \mathrm{www}$.dovepress.com/testimonials.php to read real quotes from published authors. 